\section{Pregnancy wastage associated with paracentric inversion of chromosome 13}

Habitual abortion in a 27 year old woman was investigated and a paracentric inversion (13) (q14q22) was found.

A 27 year old Pakistani woman was referred for evaluation of recurrent pregnancy loss. During the first three years of marriage her three pregnancies ended in spontaneous first trimester abortion. Past medical history was negative. Evaluation included thyroid and liver function studies, blood sugars, prolactin, and antinuclear antibody; all were normal. Endometrial biopsy revealed secretory endometrium in phase with subsequent menstruation. Mid-luteal progesterones $(\times 3)$ were each greater than $10 \mathrm{ng} / \mathrm{ml}$. Hysterosalpingogram revealed a normal uterine configuration. Mycoplasma cultures were not available. The patient and her husband were treated with doxycycline $100 \mathrm{mg}$ for 30 days on an empirical basis. Chromosome studies, performed on peripheral leucocytes with Giemsa banding, showed a normal female karyotype. However, a paracentric inversion of chromosome 13 was detected in her husband: $46, X Y$, inv(13)(q14q22) (figure).

He was a 35 year old Pakistani who had not been previously married or fathered any children. He was in good general health and was physically and mentally normal. His parents were dead. His mother had delivered eight living children, six males (including the proband) and two females. She had had no abortions. His two sisters and four brothers had normal children and no abortions. One brother's wife had experienced two first trimester spontaneous abortions and had then delivered two normal children. Chromosome analysis was not available on any of the family members.

Paracentric inversions have been associated with

Received for publication 21 January 1985.

Revised version accepted for publication 4 August 1985

*Present address: American Bio-Science Laboratories,

Van Nuys, California 91405, USA. recurrent pregnancy loss in at least three patients. Stetten and Rock ${ }^{1}$ reported a woman who had had three consecutive spontaneous abortions and exhibited a paracentric inversion of chromosome 7: 46,XX,inv(7)(p15p22). This patient also had a major uterine anomaly. Fryns and Van den Berghe ${ }^{2}$ reported a 25 year old woman with two spontaneous abortions, a normal 'clinical examination', and a mosaic karyotype: $46, X X / 46, X X, \operatorname{inv}(12)(q 12 q 24)$. This patient's third pregnancy resulted in a term female with a normal karyotype. A third case of habitual abortion was reported by Madan et al. ${ }^{3}$

In our case the documented absence of other factors known to cause recurrent pregnancy wastage strongly suggests that the paternal paracentric inversion may be associated with his wife's abortions. Because paracentric inversions are rare, it is difficult to predict the risk for subsequent abortion or abnormal liveborn children Artificial insemination by donor was discussed with this couple but was not acceptable on religious grounds. Genetic amniocentesis was recommended for any subsequent pregnancy.

Bruce G Bateman, Richard Neu*, Wallace C Nunley Jr, and Thaddeus E Kelly Department of Obstetrics and Gynecology, and Department of Pediatrics, University of Virginia Medical Center, Charlottesville, Virginia 22908, USA.

\section{References}

1 Stetten G, Rock J. A paracentric chromosomal inversion associated with repeated early pregnancy wastage. Fertil Steril 1983;40:124-6.

${ }^{2}$ Fryns $\mathrm{J}$, Van den Berghe $\mathrm{H}$. Paracentric inversion in man: personal experience and review of the literature. Hum Gene 1980;54:413-6.

3 Madan K, Seabright M, Lindenbaum RH, Bobrow M. Paracentric inversions in man. $J$ Med Genet 1984;21:407-12.

Correspondence and requests for reprints to $\mathrm{Dr}$ Bruce G Bateman, Department of Obstetrics and Gynecology, Box 387, University of Virginia School of Medicine, Charlottesville, Virginia 22908, USA.

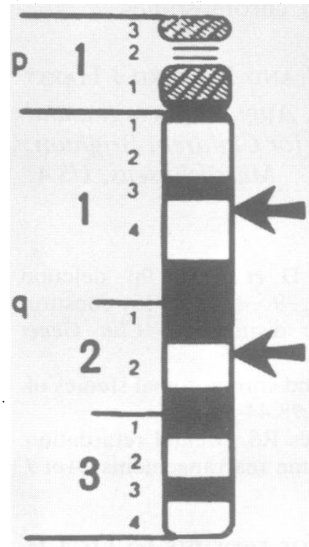

13

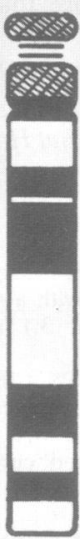

inv (13)

FIGURE Idiogram of chromosome 13, normal (left) and inverted (right). 